\title{
Mezclando manzanas con naranjas o cómo reconvenir violaciones de derechos humanos en arbitrajes de inversión
}

\author{
Uber López Montreuil ${ }^{*}$ \\ Adriana Garcés García** \\ Eduardo Dibos Figueroa***
}

Resumen. - El presente artículo evalúa una potencial reconvención de un Estado en un arbitraje de inversión. Así, se hace una revisión general de los conceptos fundamentales del arbitraje de inversión, con especial atención a las particularidades del régimen del CIADI. A partir de dichas nociones, se verificará la posibilidad de que un Estado reconvenga sobre la base del consentimiento del inversor en sus diversas manifestaciones. Por último, se desarrollarán diversos problemas que podrían presentarse en caso se invoque una vulneración a los derechos humanos como fundamento de la reconvención del Estado.

\begin{abstract}
This article analyzes potential counterclaims of a State in an investment arbitration. Thus, the authors make a general revision of the fundamental concepts of investment arbitration focus in ICSID proceedings. On that basis, they verify the possibility to support the State's counterclaim in the consent of the investor in its different manifestations. Finally, the authors develop the problems of invoke a violation of human rights as basis of the State counterclaim.
\end{abstract}

Palabras claves. - Arbitraje de inversión - Derechos Humanos - CIADI Reconvención.

Keywords. - Investment Arbitration - Human Rights - ICSID - Counterclaim.

* Estudiante de la Facultad de Derecho de la Pontificia Universidad Católica del Perú. Miembro Colaborador del Grupo Peruano de Historia del Derecho del Instituto Riva Agüero - PUCP. Co-autor del blog "Cuerdas Separadas" en Enfoque Derecho. Columnista de Radicales Libres - Revista de Derecho y Crítica. Practicante de Bullard Falla Ezcurra +. Contacto: u.lomont1@gmail.com

** Estudiante de la Facultad de Derecho de la Pontificia Universidad Católica del Perú. Practicante en Bullard Falla Ezcurra +. Contacto: dgarces@gmail.com

*** Estudiante de la Facultad de Derecho de la Universidad del Pacífico. Practicante en Bullard Falla Ezcurra+. Ganador del premio ALACDE Prize for Young Researchers 2018. Contacto: edibosf@gmail.com 


\section{Introducción}

Una tormenta se desata. La ciudad es azotada por un aguacero sin precedentes, acompañado por una de las peores tormentas eléctricas de la historia. Las calles se inundan y las casas se quedan sin fluido eléctrico. Su casa es una de las afectadas.

Pasada la tormenta es momento de reparar los daños. Las tuberías de su casa están averiadas por la inundación, al igual que las conexiones eléctricas, por la tormenta. Resulta claro que la única solución a este problema es contratar a un gasfitero y un electricista para que repare las averías de su especialidad. Sin embargo, solo logra encontrar un gasfitero. Así, tiene dos opciones, pedirle que solo repare los desperfectos de la conexión de agua y esperar por un electricista $\mathrm{o}$, pese a no ser especialista, pedirle que intente resolver los problemas del sistema eléctrico.

Algo similar viene ocurriendo en el arbitraje de inversión. Pese a que el sistema está diseñado para proteger los derechos de los inversionistas extranjeros, en los últimos años, algunos Estados vienen planteando reconvenciones por violaciones de derechos humanos. Así, se pretende que discusiones sobre temas muy distintos sean resueltas en una misma vía.

Ello ha planteado una serie de interrogantes que van desde la posibilidad misma de reconvenir en un arbitraje de inversión, hasta hacerlo alegando una violación de derechos humanos. ¿Es posible reconvenir una vulneración de derechos humanos en un arbitraje de inversión?, es la pregunta que buscaremos responder a lo largo del presente artículo. Para ello, en primer lugar, presentaremos algunas nociones generales sobre el arbitraje de inversión necesarias para nuestro análisis. Luego, desarrollaremos, de forma general, la problemática en torno a la posibilidad de reconvenir en un arbitraje de inversión; principalmente, aquella relacionada con el consentimiento de las partes para hacerlo. Finalmente, analizaremos si un Estado puede reconvenir invocando una violación de derechos humanos, por parte del inversionista.

\section{El Arbitraje de Inversión: Algunas nociones generales}

Hasta mediados del siglo pasado, cuando surgía una controversia entre un inversionista extranjero y el Estado receptor de la inversión, los inversionistas solo podían recurrir a los tribunales del propio Estado o solicitar a su país de origen la protección diplomática. Ambas vías son problemáticas. En el primer caso, el Estado es juez y parte; mientras que, en el segundo, el inversionista no participa directamente en el reclamo y su invocación depende de si su Estado de origen está o no dispuesto a hacerla suya.

El arbitraje de inversión nació como una respuesta a esta problemática. Este mecanismo de solución de controversias garantiza que el Estado receptor ya no 
sea juez y parte. El inversionista puede, ahora, acceder a una jurisdicción independiente y neutral para la reclamación de sus derechos ${ }^{1}$. Asimismo, permite que el inversionista extranjero y el Estado receptor de la inversión resuelvan sus controversias directamente, sin depender de la voluntad de su país de origen².

Las características de este sistema inciden directamente en la promoción de las inversiones extranjeras en los Estados que lo contemplan. Garantizar una vía de acción directa de los inversionistas a un mecanismo de solución de controversias imparcial otorga mayor seguridad a la inversión privada y, por tanto, promueve el desarrollo económico del Estado receptor ${ }^{3}$.

Las bondades del sistema han generado que hoy casi todos los tratados internacionales sobre inversión extranjera contemplen el arbitraje como el mecanismo de solución de controversias. Su gran difusión ha llevado a la creación de una institución especializada en la administración de este tipo de arbitrajes: el Centro Internacional de Arreglo de Diferencias Relativas a Inversiones (CIADI), institución arbitral perteneciente al Banco Mundial.

Sin embargo, pese a las virtudes del arbitraje de inversión, el acceso a este mecanismo no es irrestricto. Para poder iniciarlo se deben cumplir una serie de requisitos. Los principales son tres: (i) consentimiento, (ii) requisitos ratione personae; y, (iii) requisitos ratione materiaet. A continuación, desarrollaremos brevemente cada uno de ellos.

\section{i. Consentimiento}

La piedra de toque del arbitraje es el consentimiento. Para que este exista es indispensable que las partes hayan consentido válidamente someter sus disputas a este mecanismo de resolución de controversias ${ }^{5}$. Ello es universalmente reconocido. El arbitraje de inversiones no escapa a esta regla.

En el marco del arbitraje de inversión, este consentimiento puede derivarse de

1 KRYVOI, Yaraslau, "Counterclaims in Investor-State Arbitration", LSE Law, Society and Economy Working Papers, Reino Unido 05 de Agosto de 2011. Consultado el 10 de julio de 2019 en: http://eprints.lse.ac.uk/38469/1/WPS2011-08_Kryvoi.pdf

2 SICARD-MIRABAL, Josefa y DERAINS, Yves, Introduction to Investor-State Arbitration. Países Bajos: Kluwer Law International, 2018, pp. 41-74.

3 CHOUDHURY, Barnali, "International Investment Law and Non-Economic Issues", Reino Unido 04 de abril de 2019, Consultado el 10 de julio de 2019 en: https:// papers.ssrn.com/sol3/papers.cfm?abstract_id=3366388

4 Convenio sobre Arreglo de Diferencias Relativas a Inversiones entre Estados y Nacionales de otros Estado, suscrito en Washington D.C. el 18 de marzo de 1965, artículo 25.1 ("La jurisdicción del Centro se extenderá a las diferencias de naturaleza jurídica que surjan directamente de una inversión entre un Estado Contratante (o cualquier subdivisión política u organismo público de un Estado Contratante acreditados ante el Centro por dicho Estado) y el nacional de otro Estado Contratante y que las partes hayan consentido por escrito en someter al Centro. El consentimiento dado por las partes no podrá ser unilateralmente retirado").

5 Ver: SICARD-MIRABAL, Josefa y DERAINS, Yves. Introduction to Investor-State Arbitration. Países Bajos: Kluwer Law International, 2018, pp. 42. Ver también: REDFERN, Alan y HUNTER, Martin. Redfern and Hunter on International Arbitration. Países Bajos: Kluwer Law International, Quinta edición, 2015, p. 71. 
tres fuentes: (i) un acuerdo expreso; (ii) una ley interna; o, (iii) un instrumento internacional ${ }^{6}$.

El primer caso representa el paradigma del consentimiento. El inversionista y el Estado receptor, juntos, suscriben un acuerdo para acudir a un arbitraje de inversión ante controversia que surja entre ellos.

La mayoría de los tribunales arbitrales ha establecido que no es necesario que este consentimiento se exprese de una forma estrictamente solemne ${ }^{7}$. Al igual que cualquier otro negocio jurídico, dicho acuerdo podrá darse de distintas maneras: mediante un documento firmado por las partes, un intercambio de comunicaciones o por medio de una referencia a una cláusula de arbitraje contenida en otro documento ${ }^{8}$, entre otras.

La segunda fuente de consentimiento es una ley nacional. En este caso, el Estado receptor de la inversión formula una oferta de arbitraje en una de sus normas internas. Para que dicha oferta sea válida es indispensable que su formulación sea expresa y no deje lugar a dudas de que bastará la aceptación del inversionista para acudir a un arbitraje de inversión?.

6 CLARÓS, Pedro. "El Sistema arbitral del Centro Internacional de Arreglo de Diferencias Relativas a Inversiones (CIADI)". En Arbitration Review - Revista del Club Español del Arbitraje. Wolters Kluwer España, núm. 1, 2008, pp. 11-55.

7 Al respecto, resulta ilustrativo lo señalado por el tribunal arbitral del caso Asia Corporation y otros v. Indonesia: "[...] while a consent in writing to ICSID arbitration is indispensable, since it is required by Article 25(1) of the Convention, such consent in writing is not to be expressed in a solemn, ritual and unique formulation. The investment agreement being in writing, it suffices to establish that its interpretation in good faith shows that the parties agreed to ICSID arbitration, in order for the ICSID Tribunal to have jurisdiction over them". Ver: Asia Corporation y otros vs. República de Indonesia, Caso CIADI N ARB/81/1, Laudo, 15 de septiembre de 1983.

8 Por ejemplo, en el caso Ceskoslovenska Obchodni Banka v. Eslovaquia, se invocó la cláusula arbitral contenida en el APPRI República Checa - Eslovaquia de 1992. Ello, en la medida que esta cláusula fue referenciada en un documento contractual suscrito por las partes. Ver. Ceskoslovenska Obchodni Banka A.S. v. La República Eslovaca, Caso CIADI N ARB/97/4, Decisión del Tribunal sobre las Objeciones de Jurisdicción, 24 de mayo de 1999, \55 ("The Tribunal concludes, therefore, that by referring to the BIT, the parties intended to incorporate Article 8 of the BIT by reference into the Consolidation Agreement, in order to provide for international arbitration as their chosen dispute-settlement method. The soundness of this conclusion is confirmed by the fact that the provisions of the BIT were well known to the negotiators for both parties").

9 La importancia de que dicha oferta sea expresa e indubitable fue invocado en el caso Biwater v. Tanzania. En este, el tribunal arbitral señaló que la expresión "según lo acordado mutuamente por las partes" determinaba que la disposición contenida en la ley de inversiones de Tanzania no constituía una oferta de arbitraje. Ver: Biwater Gauff v. República Unida de Tanzania, Caso CIADI N ARB/05/22, Laudo, 24 de julio de 2008, \329 ("The first stage in BGT's argument with respect to the TIA claims is its characterization of Section 23.2 of the TIA as a unilateral, standing offer by the Republic to submit disputes to ICSID. This analysis faces the immediate - and in the Arbitral Tribunal's view insurmountable - difficulty that the options for dispute resolution in Section 23.2(a)-(c) are conditioned by the words "as may be mutually agreed by the parties". In the present context, these words are most naturally read as meaning that a dispute may be referred to any one of the three options, but only depending upon the agreement of the parties. In other words, a subsequent agreement between the parties is required - which is very different from a standing unilateral offer which simply requires acceptance by an investor. Indeed, there is no other language at all in Section 23 to suggest a standing unilateral offer by the Republic"). 
Del mismo modo, la aceptación del inversionista puede constar de distintas formas; por ejemplo, con la solicitud de arbitraje ${ }^{10}$. Solo cuando dicha aceptación se verifique, las partes quedarán vinculadas a resolver sus controversias en un arbitraje de inversión.

Por último, la tercera fuente de consentimiento son los instrumentos internacionales. En la actualidad, esta es la fuente más común de consentimiento. La mayoría de los tratados de inversión incorporan cláusulas arbitrales entre sus disposiciones ${ }^{11}$. Como en la modalidad anterior, el acuerdo arbitral se perfecciona con la aceptación del inversionista. Generalmente, dicha aceptación opera con la solicitud de arbitraje misma.

\section{ii. Ratione personae}

Como señalamos anteriormente, el arbitraje de inversión es un mecanismo en el que inversionistas y Estados resuelven sus controversias. Sin embargo, no cualquier persona, natural o jurídica, que desarrolle una actividad comercial en un Estado puede acceder a este mecanismo. Como se desprende del artículo 25 del Convenio CIADI, para hacerlo será necesario que el inversionista acredite dos requisitos: (i) ser nacional de un país distinto al del demandado y (ii) contar con una inversión en este. El requisito ratione personae se relaciona con el primer punto; mientras que el requisito ratione materiae, con el segundo.

Los criterios que cada Estado adopta para considerar como nacional a una persona, natural o jurídica, pueden ser de los más variados. Por ejemplo, en el caso de las personas naturales los Estados pueden adscribir el criterio ius soli o el criterio ius sanguinis o ambos conjuntamente. En el caso de las personas jurídicas, dicha determinación puede ser aun más compleja.

Esta libertad con la que cuentan los países puede entorpecer el tráfico comercial y la solución de controversias derivadas de estas. Ante esta situación, los Estados

10 United Nations Conference on Trade and Development. "Course on Dispute Settlement in International trade, Investment and Intellectual Property. Consent to Arbitration", 2003, p. 14. Consultado el 10 de julio de 2019 en: https:/ / unctad.org/en/Docs/edmmisc232add2_en.pdf

11 Generalmente, las cláusulas arbitrales son como la contenida en el artículo 8 del APPRI PerúFrancia: "Toda controversia relativa a una inversión entre una Parte Contratante y un nacional o sociedad de la otra Parte Contratante será amigablemente dirimida entre las partes en la controversia.

Si tal controversia hubiese podido ser solucionada en un plazo de seis meses a partir del momento en que cualquiera de las partes en la controversia la hubiera planteado, será sometida, a pedido de cualquiera de las partes, al arbitraje del Centro Internacional de Arreglo de Diferencias relativas a Inversiones (CIADI), creado por la Convención para el arreglo de Diferencias relativas a Inversiones entre Estados y Nacionales de otros Estados, firmada en Washington el 18 de marzo de 1965". Ver: Convenio entre el Gobierno de la República del Perú y el Gobierno de la República Francesa sobre Promoción y Protección Recíproca de las Inversiones, vigente desde el 30 de mayo de 1996. 
han incorporado en los tratados de inversión que suscriben definiciones sobre lo que se entiende por una persona, natural o jurídica, nacional ${ }^{12}$.

\section{iii. Ratione materiae}

El requisito ratione materiae exige que quien presenta un reclamo mediante el arbitraje realmente cuente con una inversión en el Estado receptor. Así, por ejemplo, el artículo 25(1) del Convenio CIADI circunscribe la jurisdicción de esta institución a aquellas controversias legales que estén relacionadas con inversiones. Sin embargo, este artículo no define lo que se entiende por "inversión". Ante esta indefinición, los Estados han incorporado definiciones de “inversión" dentro de sus disposiciones ${ }^{13}$. Sin embargo, esta cambia según cada instrumento internacional.

Ante la falta de una definición unánime, los tribunales CIADI han esbozado las suyas propias. En general, la jurisprudencia CIADI ha adoptado dos aproximaciones: una objetiva, que define inversión como una contribución y/o asunción de riesgo durante un tiempo determinado destinado al desarrollo económico del Estado receptor ${ }^{14}$; y una subjetiva, que analiza los elementos correspondientes a cada caso en particular (i.e. acuerdo de las partes y tratado

12 En la mayoría de los tratados, los Estados se remiten a la regulación que cada uno tiene sobre el reconocimiento de nacionalidad de personas naturales, con disposiciones como la contenida en el APPRI Perú-Alemania: “El concepto de 'Nacionales' designa: (a) Con referencia a la República del Perú: Los peruanos de acuerdo a lo establecido en la Constitución Política del Perú; (b) Con referencia a la República Federal de Alemania: Los alemanes de acuerdo a lo establecido en la Ley Fundamental de la República Federal de Alemania". Ver: Convenio entre la República del Perú y la República Federal de Alemania sobre Promoción y Protección Recíproca de Inversiones, en vigor desde el 1 de mayo de 1997, artículo 1(3). Por el contrario, en el caso de las personas jurídicas, los Estados suelen pactar definiciones particulares. Por ejemplo, en el APPRI Perú-Alemania se precisó lo siguiente: “'Sociedades' designa a todas las personas jurídicas, incluidas las sociedades civiles y comerciales y demás asociaciones con personería jurídica o sin ella, que tengan su sede en el territorio de una de las Partes Contratantes, independientemente que su actividad tenga o no fines lucrativos". Ver: APPRI Perú-Alemania, en vigor desde el 1 de mayo de 1997, artículo 1(4).

13 En la mayoría de los casos, las definiciones que incorporan los tratados internacionales incluyen una lista expresa de operaciones comerciales protegidas por estos. Por ejemplo, el APPRI PerúSuecia establece lo siguiente: "Para los fines del presente Convenio: (1) El término 'inversión' significará cualquier clase de activo, invertido por un inversionista de una Parte Contratante en el territorio de la otra Parte Contratante, a condición de que la inversión haya sido hecha de conformidad con las leyes y reglamentaciones de la otra Parte Contratante, e incluirá en particular, aunque no exclusivamente: (a) bienes muebles e inmuebles, así como cualesquiera otros derechos de propiedad, tales como hipotecas, gravámenes, prendas, usufructo, arrendamiento con opción de compra y derechos similares; (b) acciones de participación, acciones o certificados de reintegro y otras formas de participación en sociedades o sociedades de riesgo compartido; (c) derechos sobre dinero o cualquier prestación que tenga un valor económico; (d) derechos de propiedad intelectual, procesos técnicos, nombres comerciales, conocimientos tecnológicos, derechos de llave y otros similares; y, (e) concesiones conferidas por ley, decisiones administrativas o bajo contrato, incluyendo concesiones para explorar, desarrollar, extraer o explotar recursos naturales". Ver: Convenio entre el Gobierno de la República del Perú y el Gobierno del Reino de Suecia sobre Promoción y Protección Recíproca de Inversiones, en vigor desde el 1 de agosto de 1994, artículo 1(1).

14 Salini Costruttori S.p.A. y Italstrade S.p.A. v. Reino de Marruecos, Caso CIADI N ARB/00/4, Laudo, 16 de julio de 2001. 
aplicable $)^{15}$.

\section{La reconvención en el arbitraje de inversión}

Como desarrollamos líneas arriba, el arbitraje de inversión se concibió como una forma de garantizar la protección de los derechos del inversionista y el respeto a su inversión. En ese sentido, lo natural es que sean los inversionistas quienes presenten reclamos contra un Estado.

No obstante, ello no implica que un Estado no pueda reconvenir frente a la demanda de un inversionista. De hecho, permitirlo resulta beneficioso pues se asegura que no existan pronunciamientos contradictorios ante la opción del Estado receptor de acudir a un juzgado local; y, nuevamente, garantiza el acceso a un foro neutral, además de ser eficiente en términos de costo y tiempo ${ }^{16}$.

En esa línea, el propio Convenio CIADI reconoce la posibilidad de presentar un reclamo reconvencional, en su artículo 46:

"Salvo acuerdo en contrario de las partes, el Tribunal deberá, a petición de una de ellas, resolver las demandas incidentales, adicionales o reconvencionales que se relacionen directamente con la diferencia, siempre que estén dentro de los límites del consentimiento de las partes y caigan además dentro de la jurisdicción del Centro".

Como se observa, esta disposición establece que el conocimiento de las reconvenciones estará condicionado a tres requisitos: (i) su relación con la controversia, (ii) el consentimiento de las partes, y (iii) la jurisdicción del CIADI.

De estos tres requisitos, el más problemático es la existencia de consentimiento de las partes para que la reconvención proceda. Determinar si este efectivamente se ha materializado dependerá de su fuente.

Cuando la fuente del consentimiento es contractual no existe mayor conflicto. En este caso, ambas partes manifiestan su voluntad de someterse a la jurisdicción de inversiones tal y como se presenta en un arbitraje regular. Además, aquí existen obligaciones recíprocas que habilitan al Estado a alegar incumplimientos de la contraparte ${ }^{17}$.

15 SICARD-MIRABAL, Josefa y DERAINS, Yves. "Chapter 3: Jurisdiction of the Arbitral Tribunal". En Introduction to Investor-State Arbitration. Holanda: Kluwer Law International, 2018, pp. $41-74$

16 VEENSTRA-KJOS, Hege, Counterclaims by Host States in Investment Treaty Arbitration. En New Aspects of International Investment Law, 2007.

17 Ello fue confirmado en una serie de casos arbitrales frente al CIADI. Entre ellos están Adriano Gardella SpA v. Costa de Marfil, Caso CIADI No ARB/74/1, Laudo, 29 de agosto de 1977. SARL Benvenuti \& Bonfant v. República Popular del Congo, Caso CIADI N ARB/77/2, Laudo, 15 de agosto de 1980. Amco Asia Corporation y otros v. República de Indonesia, Caso Nº ARB/81/1, Laudo, 20 de noviembre de 1984. Klöckner Industrie-Anlagen GmbH y otros v. República Unida de Camerún, Caso CIADI N ARB/81/2, 21 de octubre de 1983. Atlantic Triton Company Limited v. República Popular Revolucionaria de Guinea, Caso N ARB/84/1, Laudo, 21 de abril de 1986. 
Ello no ocurre cuando el consentimiento se deriva de un tratado internacional. Como vimos, es habitual que los acuerdos de inversión contengan una oferta de los Estados para recurrir a esta vía de solución de controversias. En la mayoría de los casos nada se menciona sobre la posibilidad de plantear demandas reconvencionales.

Este asunto fue inicialmente abordado por el tribunal arbitral del caso Roussalis vs. Rumania ${ }^{18}$. En este caso, un ciudadano griego efectuó un reclamo contra el gobierno rumano producto de los cambios políticos y económicos que sucedieron en dicho país en los años 90. Roussalis invocó el BIT Rumania-Grecia para efectuar su demanda. En respuesta, el Gobierno rumano formuló una reconvención basada en el mismo acuerdo. Dicha reconvención fue desestimada por el tribunal arbitral. El principal fundamento para hacerlo fue lo dispuesto en el artículo 9 del BIT Rumania-Grecia:

"Disputes between an investor of a Contracting Party and the other Contracting Party concerning an obligation of the latter under this Agreements, in relation to an investment of the former, shall, if possible, be settled by the disputing parties in an amicable way [...]

If such disputes cannot be settled within six months from the date either party requested amicable settlement, the investor concerned may submit the dispute either to the competent courts of the Contracting Party in the territory of which the investment has been made or to international arbitration".

(Énfasis agregado)

En opinión de la mayoría de los árbitros, esta disposición solo habilita al inversionista a presentar reclamos ante el incumplimiento de las obligaciones del Estado. En este sentido, precisa que la posibilidad de presentar reconvenciones no se encuentra amparada por el tratado. Sin embargo, en este caso existió un voto disidente. Conforme a lo expuesto por el árbitro Michael Reisman, basta el artículo 46 para reconocer la facultad de los Estados para reconvenir19.

En suma, la procedencia de una reconvención dependerá del consentimiento y este, a su vez, del tipo y lenguaje del tratado invocado. Teniendo ello en cuenta, lo mejor siempre será establecer expresamente si el Estado puede o no reconvenir. Muestra de ello es el Tratado de Libre Comercio de América del Norte (NAFTA, por sus siglas en inglés), que establece que no será posible para las partes presentar demandas reconvencionales ${ }^{20}$.

18 Spyridon Roussalis v. Rumania, Caso CIADI N ARB/06/1, Laudo, 7 de diciembre de 2011.

19 Spyridon Roussalis vs. Rumania. Caso CIADI N ARB/06/01. Laudo del 7 de diciembre de 2011. Voto disidente de Michael Reisman.

20 Tratado de Libre Comercio de América del Norte, artículo 1137. Artículo 1137.- Disposiciones generales

(...)

3. En un procedimiento arbitral conforme a lo previsto en esta sección, una Parte no aducirá como defensa, contrademanda, derecho de compensación, u otros, que el inversionista 


\section{IV. ¿Puede un Estado reconvenir invocando una vulneración a los derechos humanos?}

A partir de la última década, una de las principales discusiones en materia de arbitrajes de inversión es la relacionada a la posibilidad de invocar violaciones a los derechos humanos en el marco las reconvenciones. El origen de este debate radica en los reclamos de los Estados que argumentan que la defensa de los tratados de inversión puede, a su vez, comprometer la defensa de los derechos humanos.

Sin embargo, todavía para el grueso de la academia y quienes practican el arbitraje, los derechos humanos y el arbitraje de inversión siguen siendo percibidos como ramas totalmente separadas y con pocos puntos en común. Según el profesor Dupuy, posiblemente esta percepción tiene su causa en que, por excelencia, los derechos humanos se enfocan en la defensa de la esfera jurídica de las personas naturales. Por el contrario, si bien los inversionistas pueden ser individuos, en la mayoría de los casos los reclamantes suelen ser personas jurídicas ${ }^{21}$.

Asimismo, la dinámica de los derechos humanos implica, por lo general, que los instrumentos legales funcionen como una protección de los individuos frente a los Estados. Igualmente, los Estados tienen la obligación de defender los derechos humanos de los individuos frente a las posibles violaciones por parte de personas jurídicas nacionales o internacionales. Por lo tanto, los derechos humanos "no tienen, en sentido estricto, efecto horizontal directo, en el sentido de ser aplicables, como cuestión de derecho internacional, en las relaciones entre individuos y/o corporaciones"22.

Teniendo en cuenta el marco presentado en la Sección III sobre las fuentes de consentimiento que dan pie a la reconvención de los Estados se dibuja un primer escenario en donde se vería, según la doctrina, la posibilidad que se aleguen razones de derechos humanos. Según Dumberry y Dumas-Aubin, este sería el caso en donde un tratado contenga una cláusula paraguas que cubra "todas las controversias relacionadas a inversiones" 23 .

Igualmente, otro requisito a tener en cuenta es el de la jurisdicción que poseen los tribunales CIADI para conocer los casos. ¿Su ámbito de jurisdicción abarca las reconvenciones sobre violaciones de derechos humanos? La inserción de

contendiente ha recibido o recibirá, de acuerdo a un contrato de seguro o garantía, indemnización u otra compensación por todos o por parte de los presuntos daños").

21 DUPUY, Pierre-Marie, et.al. "Unification Rather than Fragmentation of International Law? The Case of International Investment Law and Human Rights Law", Oxford: Oxford Scholarship Online, 2010, p. 46.

22 DE BRABANDERE, Eric, "Human Rights Counterclaims in Investment Treaty Arbitration". En Revue Belge de Droit International, 02 de noviembre de 2018, p. 4.

23 DUMBERRY, Patrick y DUMAS-AUBIN, Gabrielle, "When and How Allegations of Human Rights Violations can be Raised in Investor-State Arbitration", En The Journal of World Investment E Trade, vol. 13, 2012, p. 360-365. 
obligaciones específicas de derechos humanos en los tratados de inversión, junto con la posibilidad explícita de que el Estado receptor pueda reconvenir, puede representar un primer paso hacia ello ${ }^{24}$.

En primer lugar, en la práctica, la mayoría de los tratados y los contratos internacionales de inversión casi nunca se refieren a los derechos humanos de terceros o las obligaciones de los Estados en virtud de la defensa de los derechos humanos. Los tribunales, por lo general, vienen rechazando las obligaciones de derechos humanos como motivo de incumplimiento de los tratados de inversión. Los tribunales de arbitraje de inversión han opinado que es responsabilidad del Estado hacer todo lo necesario para cumplir con el derecho internacional de inversiones y sus obligaciones de derechos humanos ${ }^{25}$.

Recientemente, algunos instrumentos internacionales han empezado a incluir cláusulas en las que expresamente se establece el respeto a los derechos humanos como una obligación de los inversionistas. Por ejemplo, el Acuerdo Modelo BIT para el Desarrollo de la Comunidad del Sur de África prevé la obligación de los inversionistas de respetar los derechos humanos y cumplir con el derecho local:

\section{"Article 15.- Minimum Standards for Human Rights, Environment and Labour}

15.1. Investors and their investments have a duty to respect human rights in the workplace and in the community and State in which they are located. Investors and their investments shall not undertake or cause to be undertaken acts that breach such human rights. Investors and their investments shall not assist in, or be complicit in, the violation of the human rights by others in the Host State, including by public authorities or during civil strife (...)"26.

Por otro lado, el texto del Proyecto de Código de Inversión Panafricano27 (PAIC, por sus inglés) va más lejos y es hasta la fecha el tratado de inversión más completo cuando se trata de incluir disposiciones relacionadas con los derechos humanos $^{28}$. Además de contener disposiciones relativas a las obligaciones de los inversores en temas como responsabilidad social empresarial, corrupción y uso adecuado de recursos naturales, incluye la protección de los derechos humanos:

"Article 24 Business Ethics and Human rights

The following principles should govern compliance by investors with business ethics and human rights:

24 DE BRABANDERE, Op. cit., p. 13.

25 TAILLANT, Jorge Daniel y BONNITCHA, Jonathan. "International Investment Law and Human Rights". En Sustainable Development in World Investment Law (Cordonier Segger, Gehring and Newcombe; Jan 2011), p. 75.

26 South African Development Community Model Bilateral Investment Treaty Template. Consultado el 10 de julio de 2019 en: https://www.iisd.org/itn/wpcontent/uploads/2012/10/SADC-Model-BIT-Template-Final.pdf

27 Pan African Investment Code (PAIC) - African Union. Consultado el 10 de julio de 2019 en: https://au.int/sites/default/files/documents/32844-doc-draft_panafrican_investment_code_december_2016_en.pdf

28 DE BRABANDERE, Op. cit., p. 15. 
a. support and respect the protection of internationally recognized human rights;

b. ensure that they are not complicit in human rights abuses;

c. eliminate all forms of forced and compulsory labor, including the effective abolition of child labor;

d. eliminate discrimination in respect of employment and occupation; and

e. ensure equitable sharing of wealth derived from investments".

De acuerdo con uno de sus autores, "el PAIC pretende ser un instrumento equilibrado, lo que significa que busca un equilibrio entre la protección de la inversión y los intereses públicos no relacionados con la inversión [...]. El PAIC no deprecia la necesidad de atraer y facilitar capital extranjero a África, pero este objetivo no debe eclipsar el objetivo a largo plazo del desarrollo sostenible"29. A la fecha, el proyecto no ha sido aún adoptado ni utilizado en la práctica.

Un caso trascendental en materia de reconvención por violación de derechos humanos es Urbaser v. Argentina. En este caso, el Estado argentino reconvino en contra de la compañía, alegando que esta habría afectado el derecho humano al agua de los usuarios al no implementar la ampliación del alcance del servicio estipulada en el contrato de concesión. El Tribunal desestimó esta reconvención; sin embargo, señaló que sí era posible reconvenir en base a esta materia:

"While it is thus correct to state that the State's obligation is based on its obligation to enforce the human right to water of all individuals under its jurisdiction, this is not the case for the investors who pursue, it is true, the same goal, but on the basis of the Concession and not under an obligation derived from the human right to water. Indeed, the enforcement of the human right to water represents an obligation to perform. Such obligation is imposed upon States. It cannot be imposed on any company knowledgeable in the field of provision of water and sanitation services. In order to have such an obligation to perform applicable to a particular investor, a contract or similar legal relationship of civil and commercial law is required. In such a case, the investor's obligation to perform has as its source domestic law; it does not find its legal ground in general international law. The situation would be different in case an obligation to abstain, like a prohibition to commit acts violating human rights would be at stake. Such an obligation can be of immediate application, not only upon States, but equally to individuals and other private parties. This is not a matter for concern in the instant case" 30 .

Otro caso en el que también se presentó una reconvención en base a violaciones a los derechos humanos fue David Aven v. Costa Rica. En dicho caos, el gobierno costarricense revocó el permiso de viabilidad ambiental del hotel/club de playa

29 MBENGUE, Makane, "The quest for a Pan-African Investment Code to promote sustainable development". En International Centre for Trade and Sustainable Development - Bridges Africa, vol. 5, núm. 5, 2016. Consulta realizada el día 10 de julio de 2019. Disponible en web: https:// www.ictsd.org/bridges-news/bridges-africa/news/the-quest-for-a-pan-africaninvestment-code-to-promote-sustainable

30 Urbaser S.A. y Consorcio de Aguas Bilbao Bizkaia, Bilbao Biskais Ur Partzuergoa v. La República Argentina, ICSID Arb/07/26, Laudo, 8 de diciembre de 2016. ๆ1210. 
Las Olas, construido por empresas en las que Aven tenía acciones. Esta revocación se produjo tras constatar que el proyecto se desarrollaría en una propiedad ubicada en una zona de pantanos y de un bosque protegido. Entre los argumentos esgrimidos por el Estado, se señaló que el inversionista habría incurrido en una violación de derechos humanos. Siguiendo la línea de lo decidido en Urbaser v. Argentina, el tribunal arbitral determinó que las normas de derechos humanos tienen carácter erga omnes y, por tanto, son materia exigible incluso en el sistema de protección de inversiones:

"Under international law of investments, particularly under DR-CAFTA, the investors enjoy by themselves a number of rights both substantive and procedural, including the right to sue directly the host State when it breaches its international obligations on foreign investment (Section A of Article 10 in DR-CAFTA). What about the investor's obligations arising of the investment according to international law? This Tribunal shares the views of Urbaser Tribunal that it can no longer be admitted that investors operating internationally are immune from becoming subjects of international law. It is particularly convincing when it comes to rights and obligations that are the concern of all States, as it happens in the protection of the environment. It is pertinent to recall the observation of the International Court of Justice regarding this kind of obligations: "In view of the importance of the rights involved, all States can be held to have a legal interest in their protection; they are obligations erga omnes" 31.

En definitiva, ante los tribunales CIADI, la interacción entre el derecho internacional de inversiones y el derecho de los derechos humanos no puede ser reclamado a la ligera, ya sea por parte de los Estados o por inversionistas extranjeros. De hecho, la parte en una disputa que invoca un argumento de derechos humanos, ya sea el Estado o el inversionista, debe demostrar sustancialmente que la afectación en cuestión tiene un impacto efectivo en la implementación de la inversión en cuestión ${ }^{32}$. Esta restricción se explica por el hecho de que la jurisdicción del árbitro debe limitarse específicamente a la solución de controversias derivadas de una inversión internacional determinada.

\section{Mezclando manzanas con naranjas}

Teniendo en cuenta lo desarrollado en las secciones precedentes, todo indica que los tribunales arbitrales de inversión cada vez se muestran más abiertos a la posibilidad de analizar reconvenciones relacionadas con la violación de derechos humanos, por parte de los inversionistas. De hecho, los tratados internacionales de protección o fomento de inversiones vienen incorporando cláusulas expresas que lo permiten.

El objetivo fundamental de estas nuevas prácticas no es otro que enfrentar problemas que en la actualidad se atraviesan a nivel mundial, tales como la

31 David R. Aven y otros v. República de Costa Rica, ICSID UNCT/15/3, Laudo, 18 de septiembre de $2018, \uparrow 738$.

32 DUPUY, Pierre-Marie, et.al. Unification Rather than Fragmentation of International Law? The Case of International Investment Law and Human Rights Law. Oxford: Oxford Scholarship Online, 2010, p. 62. 
protección del medioambiente o la salud de los ciudadanos. Incorporar cláusulas de protección de derechos humanos a estos tratados es una puerta para incentivar que los inversionistas efectivamente cumplan con estos mandatos.

Así, en la actualidad, los tribunales arbitrales se enfrentan a disputas que mezclan el clásico derecho internacional de protección de inversiones con los derechos humanos. Se mezclan manzanas con naranjas. Esta fusión nos enfrenta a nuevos retos y problemas que deberán solucionarse en la práctica. Entre ellos tenemos (i) el derecho aplicable; (ii) el perfil de los árbitros; (iii) los conflictos de foro; (iv) las decisiones contradictorias; $y$, (v) los conflictos en la titularidad de los derechos. Veamos brevemente cada uno de ellos.

En relación al derecho aplicable, el sistema internacional de protección de Derechos Humanos comprende una serie de tratados. Por ejemplo, a nivel universal, los Estados se encuentran sometidos a la Carta de las Naciones Unidas y la Declaración Universal de Derechos Humanos; así como a los Pactos de Derecho Civiles y Políticos y de Derechos Económicos, Sociales y Culturales. A nivel regional tenemos la Convención Americana sobre Derechos Humanos, el Convenio para la Protección de Derechos Humanos y Libertades Fundamentales y la Carta Africana de Derechos Humanos y de los Pueblos. A estos tratados internacionales, también deben incorporarse las sentencias de las Cortes Internacionales de Protección de Derechos Humanos y las opiniones consultivas que emitan.

Permitir que en el marco de un arbitraje de inversión también se discutan controversias relacionadas a la violación de derechos humanos exige que, además de los tratados de inversión y el derecho interno aplicable, todo este marco normativo sea incorporado en el análisis del tribunal arbitral.

En esa línea, la incorporación del marco normativo y jurisprudencial en materia de derechos humanos representa un verdadero reto al momento de determinar los árbitros que conformarán el tribunal en un caso de inversión. El perfil que deberá buscarse no solo se orientará a un profesional conocedor del derecho público y comercial internacional; ahora también se deberá priorizar la experiencia en derechos humanos. Ello resulta problemático, en la medida que acota el universo de profesionales entre los cuales se puede elegir a los árbitros.

A nivel internacional existe un complejo sistema de protección de derechos humanos. Por un lado, tenemos el sistema universal que comprende una serie de comités competentes ante los cuales se pueden alegar violaciones de derechos humanos $^{33}$. Mientras que por otro, cada sistema regional de protección de derechos humanos ha implementado tribunales jurisdiccionales competentes

33 Entre los comités que conforman el sistema universal de protección de Derechos Humanos tenemos: Comité de Derechos Humanos (CCPR), Comité de Derechos Económicos Sociales y Culturales (CESCR), Comité para la Eliminación de la Discriminación Racial (CERD), Comité contra la Tortura (CAT), entre otros. 
para resolver controversias derivadas de los respectivos instrumentos internacionales aplicables.

Incluir la violación de los derechos humanos como un supuesto de reconvención en el arbitraje de inversión puede generar una serie de conflicto de foros. Al no existir una clara regulación en torno a la posibilidad de que un mismo hecho sea alegado ante una corte internacional y un tribunal arbitral, podría darse el caso de una simultaneidad de procesos.

Estos procesos paralelos en foros distintos podrían desembocar en decisiones contradictorias entre sí. Un tribunal arbitral podría declarar que efectivamente se configuró una violación de derechos humanos; mientras que una corte internacional, lo contrario; $\mathrm{y}$, viceversa.

Por último, permitir que un Estado alegue la violación de un derecho humano en el marco de un arbitraje de inversión genera un claro conflicto en relación a la titularidad para hacerlo. El sistema internacional de protección de derechos humanos reconoce a cada individuo como titular de estos. El hecho de que el Estado reclame su vulneración nos obliga a cuestionarnos el título bajo el cual lo hace: si es como titular de los mismos o como representante de los ciudadanos.

\section{Conclusión}

La responsabilidad principal de derechos humanos recae sobre los Estados que deben cumplir con la tarea de garantizarlos a lo largo de su territorio. No obstante, este paradigma puede sufrir importantes cambios a raíz de nuevas corrientes que vienen buscando entrelazar las controversias de inversión con aquellas relativas a los derechos humanos. Ello, principalmente a través del uso de las reconvenciones por parte de los Estados receptores en arbitrajes de inversión.

Aunque la jurisprudencia en temas de reconvenciones por derechos humanos es aún escasa, casos como Urbaser v. Argentina y David Aven v. Costa Rica van erigiéndose dentro del engranaje jurisprudencial del sistema CIADI como hitos obligados a ser tomados en cuenta por futuros tribunales. Igualmente, el Acuerdo Modelo BIT para el Desarrollo de la Comunidad del Sur de África y el Proyecto de Código de Inversión Panafricano representan desarrollos recientes en materia de tratados de inversión que buscan un nuevo equilibrio en la relación Estado-inversionista. Se espera que esta corriente, tanto en jurisprudencia como en tratados de inversión, tenga un desarrollo creciente durante los próximos años.

Sin embargo, no son pocos los retos que enfrenta la implementación de las reconvenciones de derechos humanos en el marco de los arbitrajes de inversión. Existen obstáculos para la extensión de la competencia de tribunales originalmente constituidos para la resolución de conflictos de inversiones hacia la revisión de presuntas vulneraciones a derechos humanos. Entre estos 
problemas, por ejemplo, se encuentran los relacionados al (i) derecho aplicable; (ii) el perfil de los árbitros; (iii) los conflictos de foro; (iv) las decisiones contradictorias; $y$, (v) los conflictos en la titularidad de los derechos. Solamente la superación de estos obstáculos por la práctica internacional junto con una mayor estandarización en la jurisprudencia podría lograr que, al momento de enfrentarse los tribunales a disputas que mezclan el derecho de protección de inversiones con los derechos humanos, no se mezclen manzanas con naranjas. 